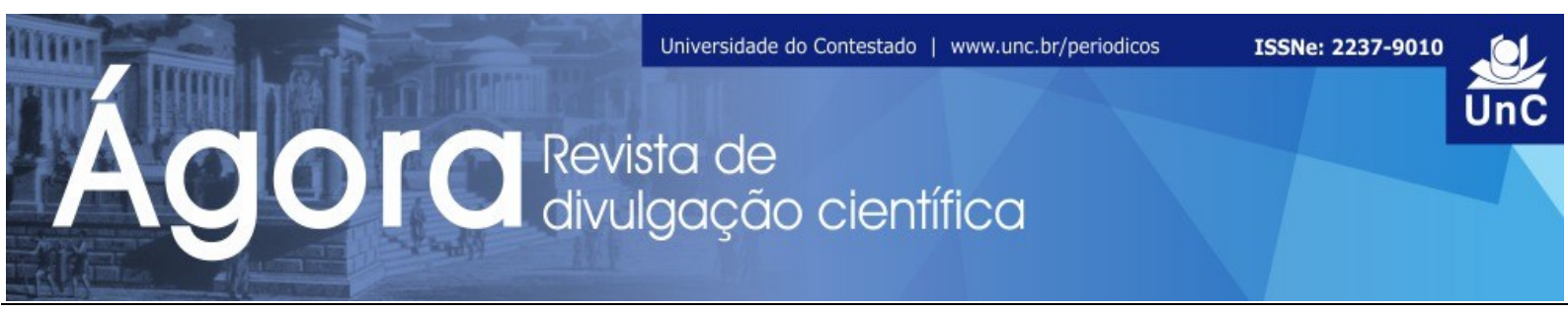

\title{
HABILIDADES SOCIAIS E EDUCAÇÃO: AVANÇOS E POSSIBILIDADES
}

Marília Mengarda Wyler $^{1}$ Josiane Schueda Raiser ${ }^{2}$

RESUMO: Relacionar Educação e Habilidades Sociais (HS) abre uma janela de possibilidades de estudo, pois na escola crianças e adolescentes desenvolvem estas habilidades (principalmente baseados na aprendizagem por modelação frente a comportamentos emitidos por colegas e professores). Um bom repertório comportamental é fator importante para o desenvolvimento de relações saudáveis, e investigar como esses conceitos vêm sendo utilizados no meio acadêmico e no trabalho de Formação Continuada de Professores torna-se importante para que ações sejam fomentadas pelo Psicopedagogo. Foram utilizadas três vertentes para a pesquisa: a pesquisa em sites de base de dados virtuais; nos Parâmetros Curriculares Nacionais; e nas Secretarias de Educação dos Municípios da Associação dos Municípios do Planalto Norte Catarinense (Ampla). A pesquisa dentro das bases de dados apontou muitos estudos sendo desenvolvidos, como o treinamento e desenvolvimento de HS dos professores, dificuldades de aprendizagem, inclusão de alunos com necessidades educativas especiais e prevenção da violência nas escolas. Nos Parâmetros Curriculares Nacionais constatou-se que o tema não é tratado com esse termo, mas é indiretamente contemplado em seu escopo. Finalmente, a pesquisa junto às Secretarias Municipais de Educação resultou numa pequena participação dos envolvidos, demonstrando pouco comprometimento com o trabalho de pesquisa. Nas Secretarias de Educação que responderam o questionário, a Formação Continuada é parte integrante da prática pedagógica, mas não há um trabalho específico utilizando as técnicas relacionadas ao tema. Os resultados apontam um ambiente propício ao trabalho do Psicopedagogo enquanto agente facilitador da Formação Continuada, principalmente quando utilizados os conceitos e técnicas relativas às Habilidades Sociais.

Palavras-chave: Habilidades Sociais. Educação. Formação Continuada de Professores.

\footnotetext{
${ }^{1}$ Psicóloga especialista em Psicopedagogia Institucional. Acadêmica da Educação à Distância da Universidade do Contestado, Santa Catarina, Brasil. E-mail: marília.wyler@gmail.com

${ }^{2}$ Mestrado em Educação pela Universidade do Oeste de Santa Catarina, Brasil (2007). Coordenador pedagógico do SENAI - ITAJAÍ, SC, Brasil. E-mail: tcceducacao.ead@unc.br
}

Ágora: R. Divulg. Cient., v. 19, n. 2, p. 40-63, jul./dez. 2014 (ISSNe 2237-9010) 


\section{SOCIAL SKILLS AND EDUCATION: PROGRESS AND POSSIBILITIES}

ABSTRACT: Relating Education and Social Skills (SS) opens a new world of study and research possibilities, since it is at school that children and teenagers develop these abilities (mainly learning through modeling, by the behavior shown by colleagues and teachers). A good behavioral repertoire is an important factor for developing healthy relationships and researches that focus on how these concepts are being used is important to develop possible actions by the psychopedagogue. The research was made on virtual database pages, in the National Curriculum Parameters (PCNs) and with the Municipal Education Bureaus in the cities of the Municipality Association of the Santa Catarina Northern Plateau (Ampla). The database research showed that there are many studies being developed, like training and development of the teachers' SS, learning problems, inclusion of students with special educational needs and violence prevention in schools. In the National Curriculum Parameters the theme was found, not exactly in the terms dealt with in this work, but with the similar idea. And the research in the municipal education bureaus resulted in a very little participation, in a demonstration of very little commitment to this research. On the bureaus that responded the survey, the continuing education is part of the pedagogic work, but there is no specific practices regarding the techniques related to SS. The results obtained point to a propitious field for the work of the psychopedagogue as a facilitator agent to continuing education, mainly when used the concepts and techniques related to the Social Skills.

Key-words: Social Skills. Education. Teacher's continuing education.

\section{INTRODUÇÃO}

O campo de estudo das Habilidades Sociais no Brasil apresenta um histórico que pode ser considerado ainda muito breve. Apesar disso, nos cerca de 40 anos em que vem sendo apresentada no país, sendo destes os últimos sete anos considerados mais significativos, muitos pesquisadores têm se interessado pelo tema e utilizando-o como base para diversos estudos e trabalhos na área, proporcionando assim uma ampla gama de resultados e perspectivas.

Dentro desses estudos, está presente frequentemente a correlação das Habilidades Sociais no contexto educacional. Sabe-se que diferentes autores já haviam postulado a íntima relação entre Educação e o contexto social e, destes, o principal nome a ser lembrado é Vygotsky, que baseou sua teoria na importância das relações sociais para explicar o desenvolvimento dos processos mentais, por exemplo. Entretanto, a partir do desenvolvimento da área de Habilidades Sociais 
(HS), essa relação pode ser vista de outra perspectiva, mais direta e com maior possibilidade de aplicação de técnicas e treinamentos.

Tomando como base a realidade atual, que demonstra cada vez mais a importância de relações sociais sadias para superar os desafios de uma sociedade altamente competitiva, o tema Habilidades Sociais adquire uma grande importância. A escola e a família surgem como ambientes propícios para crianças e adolescentes aprenderem e desenvolverem Habilidades Sociais, antes de integrarem a complexa rede de relações mais elaboradas, quando adultos. É principalmente através de modelos encontrados nos professores e colegas que eles serão capazes de entender quais são as melhores formas de expressar suas ideias, sem atingir seus colegas de uma forma negativa. Caso essas relações não estejam sendo bem desenvolvidas surgem diversos problemas, quando na falta de uma forma assertiva de se colocar no mundo, as crianças acabam agredindo seus semelhantes, através de práticas como o bullying, ou mesmo acabam se fechando por vergonha de expressar sentimentos. O efeito disso em uma sociedade do futuro (já observada em muitos adultos hoje) tende a ser catastrófica.

Sendo assim, os estudos na área de Habilidades Sociais, principalmente inserida no contexto educacional, atingem uma importância fundamental, pois tratam da aprendizagem de formas sadias de comportamento dentro um grupo social tão importante na infância e adolescência - a escola. Além disso, os professores também tendem a sair ganhando ao perceber como podem ser mais efetivos em sua prática educativa na medida em que identificam no próprio repertório comportamental o que contribui e o que pode ser mudado para desenvolver relações saudáveis com seus alunos.

A produção científica nessa área tem sido muito ampliada nos últimos anos. Apesar desse grande número de publicações percebe-se que os estudos, desenvolvidos em diferentes regiões brasileiras, acabam ficando desconectados, o que dificulta a visualização dos resultados concretos e uma possível utilização desses resultados como forma de intervenção para problemas apresentados no âmbito educacional. Partindo do pressuposto de que todos esses trabalhos científicos somente alcançam a totalidade de seus objetivos quando auxiliam na transformação/melhoria do meio e das pessoas, torna-se interessante investigar como vem se dando esse processo no que diz respeito à área de HS e Educação, 
mais especificamente à Formação Continuada de professores. Busca-se assim compreender de que forma os processos educativos e as pessoas que dele fazem parte estão sendo influenciados pelo número de pesquisas ou de que forma poderiam estar sendo afetados por elas.

Para isso faz-se necessário conhecer e divulgar quais são as iniciativas que já vêm dando certo, como estão sendo aplicados na prática os resultados dos estudos desenvolvidos nessa área no Brasil e como os agentes educacionais estão sendo atingidos por esses exemplos de casos bem sucedidos, bem como o papel dos órgãos responsáveis pelo treinamento e desenvolvimento dos professores, a saber, as Secretarias Municipais de Educação. Através dessa pesquisa buscar-se-á identificar in loco os resultados desse processo, que, sendo muito recente em nosso país, apresenta ainda um vasto horizonte de perspectivas e atuações. Baseando-se nessas informações, surgiu a problemática: Como estão sendo aplicados os resultados de estudos desenvolvidos na área de Habilidades Sociais e Formação Continuada de Professores na prática educacional atualmente?

$\mathrm{O}$ treinamento de HS pode encontrar um terreno fértil no momento da Formação Continuada de professores, uma vez que esse espaço de troca de conhecimentos funcionaria como um momento de reflexão não só das práticas pedagógicas, mas também dos comportamentos e Habilidades Sociais dos professores. Apoiado principalmente pelo trabalho psicopedagógico, acredita-se que esse tema pode ser amplamente explorado trazendo resultados positivos para todos os envolvidos.

\section{HABILIDADES SOCIAIS: CONCEITO}

Desde que foi proposta, na Inglaterra da década de 1960, a área de estudos das Habilidades Sociais vem sendo aprimorada e se reinventando dentro de uma ótica bem particular. Sendo difundida primeiramente em países de língua inglesa, foi inicialmente tratada no Brasil no final da década de 70 , mas só foi realmente assumida como uma área de interesse científico após a publicação do artigo "Habilidades Sociais: Uma área em desenvolvimento", por Del Prette e Del Prette, em 1996 (BOLSONI-SILVA et al., 2006). Somente a partir de então é que percebe- 
se um aumento significativo nas pesquisas nesse campo, surgindo como uma área ainda inexplorada e que admite um extenso campo de aplicação.

Definir Habilidades Sociais é, ainda hoje, um tema bastante discutido, mas admite-se que esse termo compreende um conjunto de comportamentos que o indivíduo apresenta frente a diversas situações sociais (DEL PRETTE; DEL PRETTE, 1999). A forma como agimos frente a essas situações é considerada pelos autores como tendo uma base genética, mas o que realmente marca o desenvolvimento dessas aptidões são as aprendizagens e os modelos desenvolvidos desde a infância, sendo esse considerado pelos autores como um período crítico para a aprendizagem das habilidades sociais.

Compõem o grupo de habilidades sociais, apesar de não ser algo fixo e acabado, componentes divididos em quatro grupos: comportamentais, cognitivoafetivos, fisiológicos e outros (DEL PRETTE; DEL PRETTE, 2002). Analisando todos esses componentes, torna-se mais fácil entender a riqueza e a complexidade de conteúdo que devemos considerar ao falarmos sobre habilidades sociais, entendendo que elas nos são repassadas durante toda a vida, através de nossas relações e interações sociais e que nossa qualidade de vida está intimamente ligada ao quão saudáveis são essas relações e como conseguimos nos expressar enquanto seres sociais.

Como se trata não só de um conceito teórico, mas também de um método prático, o campo de estudo das Habilidades Sociais contempla o Treinamento de Habilidades Sociais (THS), que apresenta programas específicos para o desenvolvimento de estratégias comportamentais com diversos grupos. As principais áreas onde o THS é empregado são a clínica psicológica, como método terapêutico para diversos transtornos como ansiedade, fobia social, timidez e isolamento social; na terapia sistêmica, como tratamento para problemas como agressividade, transtornos de personalidade antissocial e dependência química; na Psicologia Organizacional e na promoção da melhoria da qualidade de vida de idosos, por exemplo (DEL PRETTE; DEL PRETTE, 2002). Uma segunda vertente onde o treinamento de habilidades sociais é amplamente utilizado é o contexto escolar. Nesse ambiente, professores, alunos, pais e equipe diretiva podem ser envolvidos nos trabalhos, o que contempla todos os âmbitos da educação. 
Entender e relacionar Educação e Habilidades Sociais não requer muito esforço: difícil seria tentar explicar um dos termos sem nenhuma relação com o outro. Isso porque ambos tratam de habilidades e motivações humanas, necessárias ao relacionamento interpessoal e passíveis de aprendizagem e aperfeiçoamento. Não se pode negar que é na escola que a criança aprenderá e desenvolverá boa parte de seu repertório comportamental, na relação com colegas e professores. Tomando em consideração que para o desenvolvimento dessas aptidões o aluno baseia-se em grande parte no modelo que the é apresentado, o professor se torna uma figura de extrema importância dentro desse contexto, já que é considerado principalmente pelas teorias construtivista e sociointeracionista como elemento mediador entre o conhecimento e o aprendiz (LA TAILLE, 1992).

À medida que o professor mostra-se assertivo, demonstrando claramente suas ideias, sendo habilidoso para expressar sentimentos (positivos e negativos) de forma clara para os alunos, estes terão ferramentas para, em situações semelhantes, agirem de forma assertiva, pelo processo de modelação, que é um importante mecanismo de aprendizagem, caracterizado pela apreensão de comportamentos através da observação dos comportamentos de outra pessoa (BANDURA, 1979 in DEL PRETTE; DEL PRETTE, 2002).

\section{A PESQUISA NO CAMPO DAS HABILIDADES SOCIAIS}

Quando falamos em Habilidades Sociais no Brasil, não podemos deixar de mencionar os principais nomes nesse cenário, que são os professores Dr. Almir Del Prette e Dra. Zilda A. P. Del Prette. Considerados os difusores do assunto nacionalmente, vêm demonstrando interesse em reunir e organizar a produção científica nesse campo, seja participando e/ou orientando trabalhos científicos (principalmente frente à Universidade de São Carlos - UFSCar), seja na coordenação do grupo Relações Interpessoais e Habilidades Sociais (RIHS), grande responsável por reunir e divulgar esses estudos.

Atualmente a produção científica nesse cenário pode ser considerada bastante ampla, apesar da curta história apresentada no país, que é de cerca de 20 anos apenas. No primeiro artigo conceitual publicado no Brasil sobre o tema, em 1996, por Zilda e Almir Del Prette, intitulado "Habilidades Sociais: Uma área em 
desenvolvimento", falou-se das primeiras pesquisas em outros países além daqueles onde teve origem a teoria (Inglaterra e EUA na década de 30). Foi apenas nessa época que Brasil e América Latina como um todo desenvolveram e divulgaram seus primeiros estudos.

\section{A PESQUISA BIBLIOGRÁFICA EM BASE DE DADOS VIRTUAL}

A pesquisa científica, assim como a medicina, as técnicas construtivas e a transmissão de conhecimento, por exemplo, vem ao longo dos anos experimentando e sendo afetada pelas transformações da nova era. Não só a pesquisa que envolve o uso de recursos materiais, como microscópios mais potentes ou instrumentos cada vez mais precisos, mas também a pesquisa bibliográfica se beneficia da modernização, principalmente no que diz respeito à transmissão de dados obtidos.

Com o advento da internet surgiu então a possibilidade de se estar ligado com pesquisadores e consequentemente com o resultado de pesquisas do mundo inteiro, o que antigamente era praticamente impossível ou imensamente difícil, restringindose apenas a universidades mais renomadas que faziam essa troca de informações. As bases de dados surgem nesse sentido, permitindo que pesquisas em diversas áreas do conhecimento estejam disponíveis para consulta através de pesquisas cada vez mais simples e precisas.

É importante destacar que existem várias formas de se efetuar pesquisa em base de dados e que, para que se atinja uma consistência e seriedade necessária a qualquer trabalho científico, o pesquisador deve estar atento à fonte de informação de onde provêm os dados. Nesse sentido, sites com reconhecimento ou creditados a universidades e sociedades de classe devem ser considerados em contraposição aos sites de busca gerais. Tal ação permitirá uma maior credibilidade e veracidade dos resultados obtidos pela pesquisa.

\section{PSICOPEDAGOGIA E A FORMAÇÃO CONTINUADA}

Sabe-se que ao professor não cabe apenas o repasse de conhecimentos formais como conceitos matemáticos ou regras gramaticais. O professor também influencia toda a aprendizagem de conceitos sociais, valores e formas de 
comportamento que serão incorporadas pelos seus alunos. Nesse sentido, surge o papel do professor enquanto responsável por implementar e desenvolver o que Davis, Silva e Espósito (1989, in ALTENFELDER, 2005) chamam de "interações educativas", definidas como a troca de conhecimentos de uma forma menos formal, mais aberta e sem haver necessariamente uma hierarquia. Nesse caso o professor deixa de ser o detentor do saber e passa a ser um indivíduo capaz de passar seu conhecimento e experiências adquiridas ao longo de sua vida e formação aos seus alunos enquanto também aprende com eles.

Todo esse processo demanda uma especial atenção à formação docente: o trabalho do professor exige uma constante reflexão sobre sua prática, sobre a forma como interfere (positiva e negativamente) na aprendizagem de seus alunos. Ou seja, não se pode considerar apenas como necessária a formação inicial, mas sim a constante formação posterior ao ensino superior, caracterizada pela formação continuada.

Nesse sentido, a utilização das novas tecnologias e a especial atenção à forma como essa atividade de desenvolve (como por exemplo, refletir sobre as implicações da dicotomia teoria x prática o que é ensinado ou abordado em cursos de formação em serviço realmente condiz com a realidade em sala de aula? Os conteúdos trabalhados resumem-se a aspectos meramente técnicos e formais ou as questões psicossociais do professor enquanto ser humano também têm espaço?) abre um vasto campo de atuação que pode ser contemplado pelo trabalho da psicopedagogia. Isso porque o trabalho do psicopedagogo vai muito além daquele vinculado ao aluno e seus problemas de aprendizagem. $O$ trabalho interdisciplinar com a equipe pedagógica, embora menos conhecido ou divulgado, é uma das atribuições do psicopedagogo institucional e figura como um importante fator de melhoria da qualidade da educação, já que auxilia o corpo docente a encontrar alternativas para melhorar sua prática pedagógica.

O fato de ser um profissional com uma visão externa à sala de aula (ou seja, que não está tão emocionalmente ligado aos alunos ou ao professor) propicia uma maior facilidade para analisar os problemas ou dificuldades de uma forma mais imparcial. Isso porque, como cita Gatti (2003, p.192), "Os conhecimentos adquirem sentido ou não, são aceitos ou não, incorporados ou não, em função de complexos processos não apenas cognitivos, mas, socioafetivos e culturais." E acrescenta: 


\begin{abstract}
Além de geralmente enfatizarem a aquisição dos conteúdos (mais do que de habilidades), os programas de formação continuada raramente fornecem indicadores sobre a incorporação deste conhecimento à prática pedagógica de sala de aula, possivelmente devido à complexidade de se analisar essa prática e, também, à carência de procedimentos e critérios de análise do desempenho docente (GATTI, 2003, p.192).
\end{abstract}

Ou seja, programas de formação continuada que contemplem apenas a esfera cognitiva, de conhecimentos formais, podem não surtir o efeito desejado. Nesse caso, podemos situar os conceitos desenvolvidos na área de habilidades sociais como parte integrante dessa forma de se conceber um programa de formação continuada que visa não só os conteúdos formais, mas também o professor enquanto ser humano.

\title{
METODOLOGIA
}

Após a revisão bibliográfica foram escolhidas, dentro do tema proposto, algumas palavras-chave que norteariam a pesquisa propriamente dita. (Habilidades Sociais + Educação, Treinamento + Habilidades Sociais + escola e Treinamento + Habilidades Sociais + professor). Os resultados acabaram sendo muito repetitivos, pois alguns dos sites de busca escolhidos utilizam como método a consideração de apenas uma das palavras para eleger os trabalhos. Então, para especificar os resultados e evitar os incorretos, fez-se uma nova análise do tema. Considerando termos que viriam de encontro às reais necessidades da pesquisadora, decidiu-se considerar apenas um grupo de palavras-chave: "habilidades sociais + professor + formação continuada". Considerou-se substituir "treinamento" por "formação continuada" como forma de especificar a utilização do treinamento em Habilidades Sociais voltados ao trabalho de formação de professores (da Educação Infantil, Ensino Fundamental e Médio) em serviço, crendo que dessa forma os resultados estariam mais adequados ao que a pesquisa propõe-se. De toda forma, após a pesquisa procedeu-se à leitura de todos os títulos dos trabalhos sugeridos pelo mecanismo de busca do site para só então considerar os que realmente condiziam com o que a pesquisadora procurava.

Também foram eleitas três fontes de pesquisa (base de dados), a saber: 
-SciELO Brasil (Scientific Electronic Library Online - http://www.scielo.br), por se tratar de um site referência não só no Brasil mas na América Latina, muito utilizado por pesquisadores de diversas áreas do conhecimento;

-BDTD (Biblioteca Digital Brasileira de Teses e Dissertações http://bdtd.ibict.br/Teses), que reúne a produção científica no que concerne a teses e dissertações realizadas nas instituições de ensino e pesquisa brasileiras ou em desenvolvimento/orientação. A BDTD é uma iniciativa do Instituto Brasileiro de Informação em Ciência e Tecnologia (IBICT) vinculada ao que foi criado em 1954 e conta hoje com aproximadamente 200 mil teses registradas;

-RIHS (Relações Interpessoais e Habilidades Sociais http://www.rihs.ufscar.br), que é um grupo de estudos na área de HS, com sede na Universidade Federal de São Carlos, coordenado pelos professores Dr. Almir Del Prette e Dra. Zilda A.P. Del Prette. Este site reúne os principais estudos já desenvolvidos na área no Brasil, além de notícias sobre fóruns, congressos, abrangendo as principais novidades nesta área.

A escolha destas três fontes de dados justifica-se pelo fato de aumentar a dimensão de resultados e permitir três diferentes perspectivas de dados. Após digitar a palavra-chave, foi registrado o número de ocorrências fornecido pelo mecanismo de busca, seguido da leitura de todos os títulos das publicações sugeridas. A partir dessa leitura foi feita uma segunda classificação, utilizando como critérios de exclusão títulos que, mesmo contendo as palavras-chave procuradas, não contemplavam o conteúdo que a pesquisadora procurava.

Dentro dos temas que dizem respeito aos temas Habilidades Sociais e Educação, mais especificamente no que diz respeito a trabalhos desenvolvidos dentro de escolas e, ainda mais especificamente, na utilização do treinamento em HS na Formação Continuada de professores, os resultados foram compilados e analisados, através da leitura apenas dos títulos (já que nem todos os trabalhos disponibilizam resumos), dos resumos (onde não havia o trabalho disponibilizado na íntegra) e/ou dos trabalhos propriamente ditos. A partir daí pode-se verificar quais são os trabalhos que vêm sendo desenvolvidos com os professores, no que diz respeito ao Treinamento das Habilidades Sociais dentro do contexto educacional 
brasileiro nos últimos anos. Optou-se por se fazer aqui a descrição de apenas alguns trabalhos e seus autores, usando como critério os que apresentavam maior proximidade ao tema proposto, e os demais apenas citados, como forma de evitar a fuga do tema.

Também foi feita a leitura dos Parâmetros Curriculares Nacionais, objetivando identificar se o tema "Habilidades Sociais" é contemplado neste documento, além do envio de questionários e, finalmente, propôs-se a investigação do tema na prática das Secretarias Municipais de Educação, através do envio de um questionário abordando o tema Formação Continuada e Habilidades Sociais para que fosse respondido pelos secretários de Educação ou responsáveis por estas secretarias nos municípios que compõem a AMPLA-Norte (Associação dos Municípios do Planalto Norte Catarinense), composta por 10 municípios: Bela Vista do Toldo, Canoinhas, Irineópolis, Itaiópolis, Mafra, Major Vieira, Monte Castelo, Papanduva, Porto União e Três Barras.

\section{RESULTADOS E DISCUSSÃO}

\section{PESQUISA NAS BASES DE DADOS VIRTUAIS}

Iniciando a pesquisa na base de dados Scielo foram utilizadas, então, como palavras-chave, "habilidades sociais + professor + formação continuada", primeiramente na modalidade "integrada", o que forneceu apenas um resultado. Trata-se de um trabalho desenvolvido por Barrios, Marinho-Araujo e Branco (2011) sob o tema Formação continuada do professor: desenvolvendo competências para a promoção do desenvolvimento moral que, curiosamente, mesmo sem apresentar o termo Habilidades Sociais no título, propõe uma reflexão semelhante à da presente pesquisa. No caso, as pesquisadoras refletem sobre a questão do desenvolvimento moral das crianças e como isso poderia ser abordado dentro de um contexto de Formação Continuada de professores, desenvolvido com apoio de uma equipe multidisciplinar (enfatizando a figura do Psicólogo Escolar).

Buscou-se ainda outras alternativas de pesquisa disponibilizadas pelo site, sendo a primeira utilizando as mesmas palavras-chave mas dessa vez na modalidade "por palavra", o que não surtiu nenhum resultado. Partiu-se então para a 
modalidade "proximidade léxica", a qual apresentou 30 resultados. Destes, 21 tratavam de questões relativas à Educação (considerou-se apenas Educação Infantil, Fundamental e Média, excluindo cursos de formação e nível superior).

Após a leitura desses títulos chegou-se ao resultado final de 3 que apresentavam relação com o tema pesquisado. Destes destacam-se Efeitos de uma intervenção sobre a topografia das habilidades sociais de professores (Del Prette; Del Prette; Torres e Pontes, 1998), que relata os resultados de um programa chamado PRODIP - Programa de Desenvolvimento Interpessoal Profissional, desenvolvido com um grupo de professores do ensino fundamental e médio na rede pública de São Carlos/SP, durante dois meses, e que teve por objetivo desenvolver habilidades interpessoais nesse grupo. Outro trabalho intitula-se Habilidades sociais do professor em sala de aula: um estudo de caso (Del Prette; Del Prette; Garcia, Silva e Puntel, 1998), que relata os resultados do mesmo programa anteriormente citado (PRODIP), dessa vez especificamente à prática de uma professora, em forma de estudo de caso.

Nesses dois exemplos verifica-se um movimento no sentido de sistematização de um trabalho utilizando as Habilidades Sociais com o objetivo de desenvolvê-las ou melhorá-las, ou ainda tornar os professores sensíveis a essa temática a fim de que possam servir como um modelo positivo para seus alunos, além de rever sua prática pedagógica. Ambos os estudos demonstram interessantes resultados, sempre apontando avanços no que diz respeito às habilidades manifestadas pelos envolvidos após a intervenção, o que reforça a ideia da possibilidade de resultados satisfatórios caso utilizado como ferramenta no contexto de formação em serviço.

Procurando ainda por outros resultados, foram utilizadas apenas as palavraschave "habilidades sociais + professor". Na modalidade integrada foram encontrados 8 resultados, 5 dos quais tinham relação com Educação/Formação Continuada. Destes, 3 repetiram-se e já foram aqui citados; e os outros 2 referem-se ao tema, sendo Formação ética para a cidadania: reorganizando contingências na interação professor-aluno, Rocha e Carrara (2011) que relata os procedimentos e resultados positivos de um estudo desenvolvido com professores do Ensino Fundamental visando a reflexão sobre comportamentos socialmente habilidosos e sua relação 
com comportamentos éticos das crianças através de um treinamento com essas professoras.

Continuando a pesquisa, optou-se, ainda na base de dados SciELO, pela modalidade "por proximidade léxica", que não apresentou resultados. Já na modalidade "por palavra", 9 resultados foram verificados, 5 dos quais relacionavamse à Formação Continuada. O único que não se repetia relata um trabalho sobre as crenças apresentadas pelos professores e suas implicações no desenvolvimento da relação com seus alunos (Del Prette e Paiva, Crenças docentes e implicações para o processo de ensino-aprendizagem, 2009). Embora não se trate de um trabalho sobre Habilidades Sociais e Formação Continuada achou-se por bem citá-lo por trazer importantes reflexões sobre o professor enquanto avaliador de seus comportamentos e compreendendo quão ampla é a influência de sua conduta frente a uma sala de aula e aos comportamentos emitidos por seus alunos.

A base de dados da Biblioteca Digital Brasileira de Teses e Dissertações forneceu um total de 30 resultados quando digitadas as palavras-chave "Habilidades Sociais + Professor + Formação Continuada". Após efetuada a leitura dos temas dos trabalhos, 11 foram classificados por estarem relacionados ao tema formação (inicial ou continuada). Entretanto não se percebeu que esses trabalhos relacionavam-se ao que a pesquisadora procurava, pois focavam apenas na formação docente sem ter relação com as Habilidades Sociais. Alguns destacavam a visão que os professores têm sobre a formação docente e outros sobre os desafios da Formação Continuada frente às novas tecnologias e recursos midiáticos e ainda sobre formação online e em ambientes virtuais.

Buscou-se então uma nova tentativa utilizando as palavras "habilidades sociais + professor", o que resultou em 327 resultados, 26 dos quais tratavam da Formação Continuada, dentre os quais destaca-se Avaliação de programas de treinamento de professores para promover Habilidades Sociais de crianças com dificuldades de aprendizagem, onde Molina (2007) relata os resultados de uma intervenção utilizando o Treinamento de Habilidades Sociais com professores, especificamente voltado à melhoria do repertório interpessoal de alunos com dificuldades de aprendizagem, mesma temática abordada por Vila (2005), na dissertação intitulada Treinamento de Habilidades Sociais em grupo com professores de crianças com dificuldades de aprendizagem: Uma análise sobre 
procedimentos e efeitos da intervenção. Ambos os trabalhos trazem resultados demonstrando que após a intervenção houve aumento em todas as classes de Habilidades Sociais dos professores e alunos envolvidos. Isso nos leva a crer, mais uma vez, que através do desenvolvimento de HS dos professores os alunos acabam sendo diretamente favorecidos.

Em seguida foram utilizadas as palavras "habilidades sociais + formação continuada", que disponibilizou 43 resultados, cinco destes tratando do tema Formação Continuada, entretanto não apresentando relação com habilidades sociais. Nesse grupo cabe destacar o foco nas novas tecnologias, (formação continuada através da Educação a Distância (EAD) e dos ambientes virtuais de aprendizagem como uma forma de democratizar o acesso ao conhecimento a todos os professores).

A pesquisa no site do Grupo Relações Interpessoais e Habilidades Sociais (RIHS) deu-se utilizando a ferramenta de busca apresentada pelo próprio site, dentro do item "Teses e Dissertações", que por sua vez contempla os subitens "Projetos dos coordenadores", "Teses em orientação", "Dissertações em orientação", "Dissertações concluídas" e "Teses concluídas". Uma vez escrita a palavra-chave, esta é automaticamente utilizada para a pesquisa em cada um desses subitens.

Utilizando primeiramente todas as palavras, ou seja, "habilidades sociais", "formação continuada" e "professor", o site não forneceu nenhum resultado. Então se optou por fazer diferentes tentativas utilizando essas palavras e, após ler os resultados, classificar quais teriam relação com o tema proposto. Assim, ao utilizar apenas as palavras "habilidades sociais" e "formação continuada", o site disponibilizou um total de 246 resultados. Destes nem todos contemplavam assuntos relacionando as Habilidades Sociais à Formação Continuada. Após a leitura constatou-se que 53 trabalhos apresentavam relação com o contexto educacional, incluindo temas como educação especial, dificuldades de aprendizagem, treinamento de pais, entre outros. Dos 53 trabalhos pré-selecionados, observou-se que 9 podem ser enquadrados na categoria que relaciona Habilidades Sociais, professores e sua Formação Continuada.

O resultado mais significativo diz respeito à publicação intitulada Um programa de desenvolvimento de habilidades sociais na formação continuada de professores, (Del Prette, Z. A. P.; Del Prette, A., 1997) que relata os resultados do 
Programa de Desenvolvimento Interpessoal Profissional (Prodip) já tratado aqui anteriormente.

Já em Treinamento de habilidades sociais na escola: O método vivencial e a participação do professor os autores Del Prette e Del Prette (2006) relatam um trabalho realizado com alunos e professores, utilizando com o primeiro grupo o método de vivências e com o segundo o Treinamento de Habilidades Sociais, desencadeando resultados satisfatórios no que diz respeito ao relacionamento interpessoal entre professores e alunos e consequentemente no aprendizado.

Numa nova tentativa por resultados, fez-se a utilização das palavras "habilidades sociais" e "professor". Nesse caso o mecanismo de busca indicou um total de 74 resultados, dentre os quais pode-se encontrar cinco que apresentavam alguma relação com Formação Continuada. No trabalho Desenvolvimento socioemocional na escola e prevenção de violência: Um programa de treinamento e orientação de professores (2000-2003), Zilda Del Prette faz uma reflexão sobre como dificuldades de aprendizagem e fracasso escolar interferem nas relações sociais dos alunos com seu meio e sugere a organização do material já produzido por ela na área de Habilidades Sociais e Educação como forma de atingir o maior número de professores, alunos e agentes educacionais para essa temática, através da informatização dos instrumentos de coleta de dados, publicação de um livro sobre Habilidades Sociais e problemas de aprendizagem e um manual do professor de forma a instruí-los a avaliar e promover Habilidades Sociais nas escolas.

Mais uma vez observou-se uma grande quantidade de trabalhos relacionados à Formação Continuada na prevenção ou tratamento das dificuldades de aprendizagem, dentre eles a tese escrita por Molina (2002-2006) com o título Capacitação de professores para a promoção do desempenho social e acadêmico de alunos com dificuldades de aprendizagem. A autora descreve que os resultados mostraram que, após a intervenção proposta e avaliação dos professores, os alunos demonstraram estar mais assertivos, participativos e empáticos, o que nos leva a crer que o trabalho trouxe benefícios visíveis sobre as Habilidades Sociais apresentadas pelos alunos. 
HABILIDADES SOCIAIS NOS PARÂMETROS CURRICULARES NACIONAIS PCNS

Os Parâmetros Curriculares Nacionais surgiram da necessidade de se criar um referencial que pudesse ser adotado em todas as escolas do território nacional, e trata-se de um conjunto de temas propostos após muitos estudos interdisciplinares, que se divide basicamente em dois blocos: Ensino Fundamental e Ensino Médio. Ao contrário do que se pode pensar não estão contidos nos PCNs fórmulas prontas ou conteúdos engessados, mas sim possibilidades, sugestões e ideias que podem e devem ser discutidas e repensadas pelas escolas, seus professores e equipe diretiva, durante o planejamento anual de atividades e ao longo do ano letivo.

Tendo por objetivo descobrir se em algum momento o tema Habilidades Sociais é contemplado nos Parâmetros Curriculares Nacionais - mais especificamente na Educação Infantil e Ensino Fundamental I e II - deu-se a leitura do referido documento, considerando principalmente os temas transversais.

Ao se considerar o conteúdo e toda a estrutura contida nos PCNs, percebe-se que o foco do trabalho volta-se à educação para a cidadania, colocando inclusive que esta é uma tendência mundial. Seja no que tange aos conteúdos essenciais das áreas de conhecimento consideradas "formais", como Matemática ou História, seja nos chamados Temas Transversais (Meio Ambiente, Saúde etc.), no Ensino Fundamental ou Médio, temas como relações sociais, respeito às diferenças e formação de cidadãos são citados inúmeras vezes.

Entretanto, após realizada a pesquisa nos PCNs não foram encontradas citações relativas à consideração das Habilidades Sociais como tema a ser abordado em sala de aula, pelo menos não com esse termo. Não se pode afirmar, portanto, que esse tema não seja contemplado pelos Parâmetros Curriculares Nacionais, visto que as Habilidades Sociais são um conjunto de comportamentos necessários para o bom desenvolvimento das relações interpessoais. É claro que comportamentos também podem ser ensinados e aprendidos, mas o que ocorre é que essas condutas acabam sendo repassadas aos alunos intrinsecamente dentro de outras disciplinas e também nas próprias relações estabelecidas entre alunos e professores. 
FORMAÇÃO CONTINUADA NAS SECRETARIAS MUNICIPAIS DE EDUCAÇÃO

Primeiramente o questionário foi elaborado e aprovado pela orientadora do projeto. Em seguida buscaram-se nos sites das já citadas prefeituras os contatos por e-mail com as secretarias de Educação para o posterior envio dos questionários acompanhados de uma apresentação da pesquisadora e explanação sobre os objetivos da pesquisa, salientando o sigilo dos dados e sugerindo um prazo de 20 dias para o retorno dos questionários respondidos.

Passado o prazo sugerido não houve retorno de nenhuma secretaria. Achouse por bem então enviar novo e-mail às 10 secretarias questionando sobre o recebimento do e-mail e sobre possíveis dificuldades quanto ao preenchimento do questionário. Após esse novo contato os(as) secretários(as) ou responsáveis pelas Secretarias de 6 municípios retornaram o contato, alguns alegando que não haviam recebido o questionário, outros que não houve tempo hábil para responder as questões, mas mostrando-se interessados em participar da pesquisa. Efetuou-se então o reenvio dos e-mails com os questionários com um prazo estendido para o retorno dos mesmos, sendo que após passado o prazo apenas 2 questionários foram devolvidos. Para preservar os dados dos municípios participantes utilizar-se-á aqui a denominação "Município A" e "Município B" para a apresentação das respostas.

A primeira questão abordada foi o tempo em que cada secretário(a) ou responsável estava à frente da Secretaria de Educação, pensando ser esse um dado relevante já que no início desse ano houve em muitos municípios a troca de prefeitos e sucessivamente a troca de equipes administrativas, influenciando assim todo o planejamento e desenvolvimento de atividades por parte das secretarias. No caso do Município "A" o secretário desenvolve suas atividades há dois anos e meio, enquanto no município "B" o cargo é ocupado por essa pessoa há 6 meses.

Os responsáveis foram questionados sobre a frequência com que são desenvolvidos cursos de formação continuada para professores nos municípios pesquisados, ressaltando se há um cronograma/planejamento para o desenvolvimento dessas atividades. O município "A" respondeu que há sim essa preocupação, que os cursos são realizados envolvendo todos os profissionais da rede, e que os cronogramas são definidos através do Plano Plurianual (PPA), mas 
não especificou a frequência com que são aplicados. Já o município "B" respondeu que o cronograma de cursos é elaborado geralmente no início do ano e que os cursos são realizados no recesso escolar do mês de julho, podendo também ser realizados no período noturno durante todo o ano caso haja necessidade.

Em seguida, foram questionadas as estratégias utilizadas para efetivar os resultados dos treinamentos de professores. O representante do município "A" relatou que há um acompanhamento através dos planejamentos diários dos professores, onde se pode perceber a efetiva utilização por parte do corpo docente dos métodos e estratégias aplicadas nas formações continuadas. Para ele, o resultado advém do conjunto entre a formação continuada, Plano Plurianual (PPA), Diretrizes Curriculares Municipais, além da verificação das atividades pelos profissionais de apoio (Pedagogos, Orientadores Educacionais e Diretores das Unidades). No município "B" os resultados do trabalho de formação continuada são constatados através de monitoramento dos dirigentes escolares, planilhas e atividades do calendário escolar, o que segundo ele traz consequências no processo avaliativo dos alunos, de acordo com o planejamento, programação e temas dos cursos.

Após investigação sobre formação continuada, propôs-se ainda um questionamento sobre a definição de Habilidades Sociais, obtendo-se como resposta do Município "A" que Habilidade Social é "o comportamento de uma pessoa ou modo de agir, falar, se manifestar que em dado momento ou circunstância são utilizados para enfrentar ou solucionar um problema." (sic). Para o representante do município "B" Habilidades Sociais "têm muito a ver com relacionamento interpessoal, as diferentes capacidades que o indivíduo tem em relacionar-se, os comportamentos sociais de cada indivíduo" (sic). Além da definição investigou-se se essa temática é considerada importante nas escolas no ponto de vista dos entrevistados, o que trouxe, em ambas as respostas, a extrema importância do tema principalmente porque "[...] frente a todos os desafios impostos pela atuação no Magistério, nossos colaboradores são testados diariamente em suas habilidades sociais, na comunicação com os alunos, colegas de trabalho, direção da escola, pais e toda a comunidade que espera deste profissional sempre "algo a mais"." (sic - Município "A"). 
Finalmente questionou-se se há (ou já houve) nos municípios pesquisados um programa de treinamento de Habilidades Sociais voltado para os professores da rede municipal de ensino ou para os alunos. Caso a resposta para essa questão fosse negativa, questionou-se se eles considerariam a possibilidade ou necessidade disso nas escolas. No município " $A$ " não houve tal treinamento especificamente abordando este tema, mas dentro da formação continuada ele é indiretamente trabalhado. No município "B" já houve algumas palestras voltadas a Habilidades Sociais para os professores, mas para os alunos não.

\section{CONCLUSÃO}

Partindo da pesquisa nas três bases de dados utilizadas, pode-se perceber que há um grande número de trabalhos que enfocam as Habilidades Sociais como ferramenta utilizada na Formação Continuada de professores.

Constatou-se que os principais métodos de pesquisa são os grupos de controle, com a aplicação de pré e pós-testes e posterior avaliação (quantitativa e qualitativa). Além disso, percebeu-se que o Treinamento de Habilidades Sociais (THS) também foi amplamente utilizado, principalmente com os professores. Infelizmente não foi possível conhecer e descrever precisamente tais técnicas, visto que muitos trabalhos estão disponíveis apenas na forma de resumos (alguns deles nem mesmo apresentavam os resumos), o que acaba por fornecer dados muito sucintos.

Quanto aos temas relacionados nos trabalhos, além de abordar a Formação Continuada baseada no desenvolvimento de Habilidades Sociais, foram constatados muitos trabalhos focando as dificuldades de aprendizagem dos alunos e buscando intervir nesses problemas desenvolvendo HS tanto dos alunos quanto dos professores. Além disso, foram encontradas referências às novas tecnologias aplicadas à Educação, à importância da Formação Continuada como forma de melhorar a qualidade da Educação, além de trabalhos desenvolvidos no contexto da inclusão de alunos com necessidades educativas especiais e prevenção da violência nas escolas através do fortalecimento das relações interpessoais entre alunos e entre professor-aluno. Em todos eles o que chama a atenção é o fato de abrir um 
espaço e permitir que o professor reveja suas ações e sua prática pedagógica, espaço esse que nem sempre é explorado nas escolas.

Em nenhum trabalho ficou claro se houve alguma parceria com as Secretarias Municipais de Educação para o desenvolvimento dos trabalhos de Formação Continuada, não se podendo afirmar se essa atitude não ocorreu ou se a informação foi apenas omitida.

Num segundo momento, trazendo os dados oferecidos pelos Parâmetros Curriculares Nacionais - PCNs acredita-se que, embora não citando especificamente os termos pesquisados (HS e Formação Continuada), este documento contempla em seus textos a ideia central aqui analisada: a importância de se trabalhar no contexto educacional as relações interpessoais e as habilidades necessárias para o fomento de relações saudáveis entre os seres. E nesse sentido estão englobados professores, alunos, equipe diretiva, pais e comunidade escolar, como uma rede de corresponsáveis pelo crescimento e desenvolvimento da Educação como um todo.

Aqui cabe um adendo sobre a importância do trabalho do Psicopedagogo Institucional, que, uma vez detentor dos conhecimentos sobre o contexto educacional no qual trabalha e seus envolvidos, e tendo o privilégio de poder fazer uma análise à distância desse contexto, pode auxiliar em muito a efetivação de trabalhos envolvendo professores (num trabalho de Formação Continuada) e também alunos (diretamente ou através de proposição de atividades aos professores), englobando o melhoramento das Habilidades Sociais.

Cabe ainda refletir sobre os dados obtidos com os questionários remetidos às Secretarias Municipais de Educação. Estes demonstram que a Formação Continuada está presente como parte integrante do planejamento anual das instituições, embora não tenha ficado claro quais estratégias são utilizadas nessa formação, e que os resultados são analisados através do contato direto com os dirigentes escolares, além de dados obtidos por planilhas e o próprio processo avaliativo pelo qual os alunos são submetidos.

Ambos os participantes demonstraram uma boa noção sobre o que vem a ser Habilidades Sociais e entendem que esse é um tema de fundamental importância a ser tratado tanto com professores como com os alunos, apesar de não ter sido abordado em um dos municípios no contexto da Formação Continuada. Revela-se, 
então, uma rica possibilidade para ser trabalhada no futuro, seja pelos profissionais que já atuam nas secretarias ou mais especificamente por um profissional de Psicopedagogia.

Tratando agora todos os resultados obtidos desde o envio dos questionários às prefeituras, muitos fatos podem ser trazidos para análise e reflexão. Primeiramente cabe destacar o fato de apenas duas das 10 prefeituras envolvidas terem devolvido seus questionários preenchidos. Não se pode afirmar o que realmente tenha causado tal fato, mas dentre as possíveis hipóteses para tal podese citar a falta de tempo dos profissionais envolvidos, a falta de interesse por não ver a pesquisa como um fator relevante de mudança, pelo tema tratado ou ainda o fato de não ser algo muito comum às Secretarias, já que geralmente as pesquisas restringem-se ao ambiente universitário ou escolar sem envolver os responsáveis pela administração pública diretamente. Infelizmente buscava-se maior riqueza de dados e experiências, mas o fato de apenas duas prefeituras terem respondido o questionário também nos permite implementar essa análise sobre o contexto educacional principalmente no que se refere ao padrão de comportamento adotado pelos responsáveis ao se absterem inclusive de enviar um e-mail à pesquisadora informando que preferiam não participar da pesquisa.

A grande contribuição desse estudo está no fato de se poder relacionar três possibilidades de dados: uma pesquisa mais teórica, sobre o que há de oficial tratando do tema, contemplado pelos Parâmetros Curriculares Nacionais, que, como já destacado, mesmo que em outras palavras, tratam da importância do trabalho das Habilidades Sociais dentro das escolas; os dados trazidos por pesquisadores em todo o Brasil, com uma riqueza de resultados obtidos quando se aplicam técnicas de Treinamento de HS no contexto educacional, como uma proposta para o desenvolvimento de pessoas e consequentemente da sociedade; e, finalmente, trazendo para uma realidade mais específica, o trabalho desenvolvido pelas Secretarias Municipais de Educação enquanto responsáveis pelo aperfeiçoamento de seus profissionais como parte inseparável de uma Educação de qualidade.

Acredita-se que, mais do que apresentar um resultado quantitativo demonstrando que uma porcentagem de pessoas age de uma forma ou um número " $x$ " de secretarias utilizam a técnica de Treinamento de Habilidades Sociais entre os professores, por exemplo, é importante o fato de os dados terem uma relevância 
qualitativa e, mais do que isso, estimularem os envolvidos a uma continuação dos estudos e da pesquisa em si. Isso porque tomando tudo o que foi apresentado abrese um campo ainda mais amplo, trazendo a possibilidade de, baseando-se nos dados até aqui colhidos, ampliar o número de envolvidos na pesquisa e desenvolver possíveis estratégias de aplicação do Treinamento de Habilidades Sociais nas escolas ou entre as Secretarias de Educação. Dessa forma torna-se possível colaborar com a transformação e melhoria do cenário educacional, partindo do trabalho com o corpo docente, que se reflete posteriormente em sala de aula, além da valorização do trabalho do profissional Psicopedagogo dentro das instituições de ensino.

\section{REFERÊNCIAS}

ALTENFELDER, A.H. Desafios e tendências em formação continuada, Revista Construção psicopedagógica, São Paulo, v. 13, n. 10, 2005. Disponível em: $<$ http://pepsic.bvsalud.org/scielo.php?pid=S141569542005000100004\&script=sci_arttext> Acesso em: 18 jan. 2012.

BANDEIRA, DEL PRETTE; DEL PRETTE. "Treinamento de habilidades sociais na escola: O método vivencial e a participação do professor”. em: Estudos em Habilidades Sociais e relacionamento interpessoal. São Paulo: Casa do Psicólogo, 2006.

BOLSONI-SILVA, A.T. et al. A área de Habilidades Sociais no Brasil: Uma análise dos estudos publicados em periódicos, 2006. Disponível em:

$<$ http://www.rihs.ufscar.br/armazenagem/pdf/capitulos-de-livro/capitulo-1-a-area-dehabilidades-sociais-no-brasil-uma-analise-dos-estudos-publicados-em-periodicos> Acesso em: 20 dez. 2012.

BOLSONI-SILVA, A.T. ; MATURANO, E. M. Práticas educativas e problemas de comportamento: uma análise à luz das habilidades sociais. 2002. Disponível em: <http://www.scielo.br/pdf/\%0D/epsic/v7n2/a04v07n2.pdf>. Acesso em: 20 dez. 2012.

BRASIL. Secretaria de Educação Fundamental. Parâmetros curriculares nacionais: terceiro e quarto ciclos do ensino fundamental. Secretaria de Educação Fundamental. - Brasília : MEC/SEF, 1998.

CABALLO, V. E. Manual de Técnicas de Terapia e Modificação do Comportamento. São Paulo: Ed. Santos, 1996. 
DEL PRETTE, Z. Desenvolvimento socioemocional na escola e prevenção da violência: Um programa de treinamento e orientação de professores. Auxílio CNPq -Bolsa Pq-1C e Bolsas IC, 2000-2003.

DEL PRETTE, Z.; DEL PRETTE, A. Desenvolvimento interpessoal e educação escolar: o enfoque das habilidades sociais, 1998. Disponível em:

$<$ http://pepsic.bvsalud.org/scielo.php?pid=S1413-

389X1998000300005\&script=sci_arttext>. Acesso em: 12 jan. 2013.

Petrópolis: Vozes, 1999.

Psicologia das habilidades sociais: Terapia e educação.

. Um programa de desenvolvimento de habilidades sociais na

formação continuada do professor. CD-Rom "Melhores Trabalhos". Associação Nacional de Pesquisa em Educação (ANPED), 1997.

Reflexão e Crítica, 1996.

Habilidades sociais: Uma área em desenvolvimento. Psicologia

DEL PRETTE, A. et al. Efeitos de uma intervenção sobre a topografia das

habilidades sociais de professores. Psicologia Escolar Educacional, Campinas, v.2. n.1, 1998.

GATTI, B. A. Formação continuada de professores: a questão psicossocial.

Cadernos de Pesquisa, n. 119, 2003.

LA TAILLE, Y. Piaget, Vygotsky, Wallon: terorias psicogenéticas em discussão.

São Paulo: Summus, 1992.

MOLINA, R. C. M. Capacitação de professores para a promoção do desempenho social e acadêmico de alunos com dificuldades de aprendizagem. Programa de Pós-Graduação em Educação Especial - UFSCar, 2002-2006.

MOLINA, R. C. M. Avaliação de programas de treinamento de professores para promover habilidades sociais de crianças com dificuldades de aprendizagem. Tese (Doutorado) - Programa de Pós-graduação em Educação Especial da UFSCar, 2007 São Carlos, 2007.

MOLINA, R. C. M.; DEL PRETTE, Z. A. P. Construção de um programa de formação continuada de professores para a promoção de repertório social e acadêmico em alunos com dificuldades de aprendizagem. Anais de Trabalhos Completos da Anpedinha: Associação Nacional de Pesquisa em Educação, 2005.

MURTA, S.G. Aplicações do Treinamento em Habilidades Sociais: Análise da Produção Nacional. Psicologia: Reflexão e Crítica, 2005.

PAIVA, M. F.; DEL PRETTE, Z. A. P. Crenças docentes e implicações para o processo de ensino-aprendizagem. Revista Semestral da Associação Brasileira de Psicologia Escolar e Educacional (ABRAPEE), v. 13, n. 1, jan./jun. 2009. 
PINOLA, A. R. R. Efeitos de um programa de treinamento de habilidades sociais educativas junto a professores de alunos com deficiência mental incluídos. Programa de Pós-Graduação em Psicologia - USP Ribeirão Preto, 2006-2010.

ROCHA, J. F. ; CARRARA, K. Formação ética para a cidadania: reorganizando contingências na interação professor-aluno. Psicologia Escolar e Educacional, Maringá, v. 15, n. 2, 2011.

ROMANOWSKI \& MARTINS. Formação continuada: contribuições para o desenvolvimento profissional dos professores. Revista Diálogo Educacional, Curitiba, v. 10, n. 30, p. 285-300, maio/ago. 2010.

VILA, E. M.; DEL PRETTE, A. Relato de um programa de treinamento de habilidades sociais com professores de crianças com dificuldadesde aprendizagem. In: S. R. de Souza, \& V. B. Haydu. (Org.), Psicologia Comportamental Aplicada: Avaliação e intervenção nas áreas do esporte, clínica, saúde e educação. Londrina: EDUEL.

2009

VILA, E. M. Treinamento de habilidades sociais em grupo com professores de crianças com dificuldades de aprendizagem: uma análise sobre procedimentos e efeitos da intervenção. São Carlos, UFSCar, 2005.

Artigo recebido em: 01/04/2014

Artigo aprovado em: 27/05/2015 